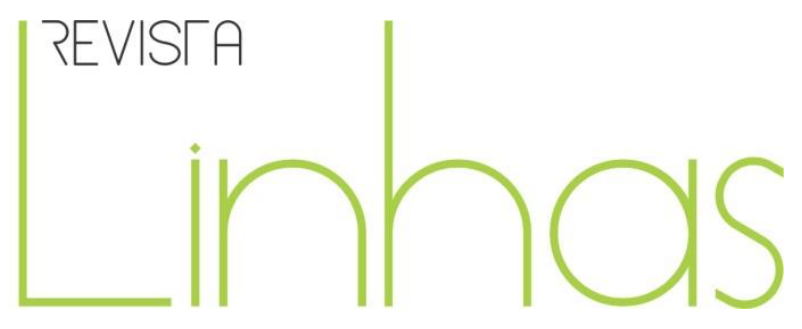

\title{
Narrativas sobre avaliação e Design Universal no ensino superior do estado do Ceará, Brasil
}

\begin{abstract}
Resumo
Este estudo pretende apresentar as narrativas acerca da avaliação e design universal de aprendizagem com base na percepção dos discentes do curso de graduação em Pedagogia na modalidade semipresencial de uma instituição pública, nas cidades de Beberibe, Brejo Santo, Caucaia, Itapipoca, Orós, Sobral e Russas, do estado do Ceará. Quanto ao aspecto metodológico, a investigação desenvolvida corresponde a uma pesquisa descritiva com abordagem qualitativa aplicada a 110 (cento e dez) acadêmicos da referida instituição. A análise qualitativa foi realizada com o apoio do Atlas.ti.8, com vistas a entender as narrativas provenientes dos discentes para a compreensão de um novo design para avaliação, para o ensino e para aprendizagem, além de permitir identificar os desafios, limites e contribuições do Design Universal para Aprendizagem (UDL). Os resultados evidenciaram efetivas contribuições do modelo UDL para aprendizagem, para o desenvolvimento da autonomia, acessibilidade e rompimento de barreiras metodológicas no contexto educativo, tornando-o mais democrático e participativo.
\end{abstract}

Palavras-chave: Avaliação educacional. Design Universal para Aprendizagem. Educação superior.
Marcos Antonio Martins Lima

Universidade Federal do Ceará UFC - Fortaleza/CE - Brasil marcos.a.lima@terra.com.br

\section{Maria Lucijane Gomes de Oliveira} Universidade Federal do Ceará UFC - Fortaleza/CE - Brasil luciijanne.oliveira@gmail.com

\section{Para citar este artigo:}

LIMA, Marcos Antonio Martins; OLIVEIRA, Maria Lucijane Gomes de. Narrativas sobre avaliação e design universal no ensino superior do estado do Ceará, Brasil. Revista Linhas. Florianópolis, v. 21, n. 45, p. 341-362, jan./abr. 2020.

\section{DOI: $10.5965 / 1984723821452020341$}

http://dx.doi.org/10.5965/1984723821452020341 


\title{
Narratives on universal evaluation and design in higher education in the State of Ceará, Brazil
}

\begin{abstract}
This study intends to present the narratives about the evaluation and design of universal learning based on the perception of the undergraduate students in Pedagogy in the semi-private modality of a Public Institution in the cities of Beberibe, Brejo Santo, Caucaia, Itapipoca, Orós, Sobral and Russas, from the State of Ceará. As for the methodological aspect, the research developed corresponds to a descriptive research with a qualitative approach applied to 110 (one hundred and ten) scholars of the said Institution. The qualitative analysis was carried out with the support of Atlas.ti8 in order to understand the narratives coming from the students to the understanding about a new design for evaluation, for teaching and learning, and to identify the challenges, limits and contributions of the universal design for learning (UDL). The results evidenced the effective contributions of the UDL model to learning, to the development of autonomy, accessibility and breakdown of methodological barriers in the educational context, making them more democratic and participatory.
\end{abstract}

Keywords: Educational evaluation. Universal design. College education. 
O material didático de qualidade é preocupação fundamental para o alcance dos objetivos pretendidos, tendo em vista que é um dos mais respeitáveis "recursos de aprendizagem, uma vez que é capaz de viabilizar e tornar factíveis os ideais filosóficodidático-educacionais explicitados nos projetos pedagógicos dos cursos" (TIZIOTTO; OLIVEIRA NETO, 2010, p. 1). Partindo desse pressuposto, surge a necessidade de investigar as possibilidades do planejamento fundamentado no design universal como uma estratégia colaborativa para o processo de aprendizagem. Em função disso, o uso de design universal aplicado à avaliação na educação superior pode indicar possíveis reduções em índices de evasão nos cursos, haja vista que, atendendo às expectativas do aluno, estes se tornam atraídos e confiantes a continuar no modelo pedagógico alternativo de educação mais flexível e menos burocrático (GOMES et al., 2010).

Diante do exposto, a pergunta que norteia esta pesquisa é: como as ações didático-avaliativas têm acontecido no curso de Pedagogia, modalidade semipresencial, de uma instituição pública, de modo a contribuir para a aprendizagem? Assim, surgem alguns questionamentos, a saber: quais os desafios para a aprendizagem no curso? Quais as limitações? Quais as contribuições do modelo Design Universal para Aprendizagem (Universal Design for Learning - UDL) para avaliação do curso?

Para responder essas perguntas, buscamos apresentar as narrativas acerca da avaliação e de design universal de aprendizagem com base na percepção dos discentes do curso de Pedagogia de uma instituição pública. Os objetivos específicos são: identificar os desafios da inserção das práticas UDL; refletir sobre as limitações do uso das estratégias UDL no processo educativo; e enfatizar as contribuições do uso das práticas didático-avaliativa UDL no processo de aprendizagem.

Os aspectos metodológicos do estudo compreendem uma pesquisa de campo, descritiva com abordagem qualitativa aplicada a 110 (cento e dez) acadêmicos do curso de graduação em Pedagogia, modalidade semipresencial de uma instituição pública, nos polos presenciais das cidades de Beberibe, Brejo Santo, Caucaia, Itapipoca, Orós, Sobral e Russas, do estado do Ceará (CE). 
Em relação ao seu desenvolvimento, o artigo está estruturado em mais cinco seções, além desta introdução. A segunda seção traz o referencial teórico no qual são aprofundados conceitos do estudo, abordando avaliação e design universal em processos educativos, enfatizando o modelo Design Universal para Aprendizagem. A terceira seção aborda os aspectos metodológicos do estudo. A quarta apresenta os resultados e as análises e, por fim, na quinta seção são feitas as considerações finais.

\section{Design Universal de Aprendizagem e avaliação: considerações epistemológicas e conceituais}

Esse tópico parte de uma visão epistemológica e conceitual do termo design para então especificar para o termo "design universal para aprendizagem”, visando o seu entendimento e suas implicações no ambiente educacional. Design significa "criar ou planejar com um propósito específico. Em latim, designáre quer dizer marcar, indicar; e em francês designer quer dizer designar, desenhar" (ALVES, 2016, p. 30).

A história do design como campo de conhecimento surge com maior relevância a partir da Revolução Industrial, em que emerge no cenário mundial a necessidade de um novo modelo de produção. De fato, anterior a esse período, os artesãos já projetavam e construíam os bens que produziam, considerando, suas especificidades geográficas, físicas e históricas. Assim, a partir da modernização advinda da Revolução Industrial, surgem, portanto, padrões estabelecidos para a produção dos bens, de forma a serem comercializados no mercado em massa (CAVALCANTI; FILATRO, 2016).

Desse modo, a compreensão contemporânea de design transformou-se em uma ferramenta poderosa de produção comandada por profissionais com especialidades em projetar artefatos industriais, "a princípio, físicos e analógicos, mas, posteriormente, também culturais, digitais e virtuais" (CAVALCANTI; FILATRO, 2016, p. 2).

Assim, de acordo com Cavalcanti e Filatro (2016), as principais vertentes do campo do design, são: (i) Design de Produtos e Design Industrial que ocorreu a partir da Era Industrial (final do século XVIII e início do século XIX); (ii) Design de bens, informação e identidades, desencadeado a partir da era do consumismo (1950); (iii) Design de interfaces provocado pela popularização dos computadores pessoais nos anos de 1970 e 
1980; (iv) Design centrado no usuário, quando surge maior preocupação com os usuários de produtos e serviços, a partir de 1980 e; v) Design de redes de multiusuários, com a popularização da internet na década de 1990. Na década de 2000, surge no campo do design uma atenção maior aos aspectos sociais e humanos.

Contudo, para melhor compreender o termo design é preciso entender as diferentes dimensões, quais sejam: design como profissão, processo, produto e modo de pensar. A princípio, os designers eram contratados como "colaboradores autônomos com o objetivo de criar produtos que fossem funcionais e esteticamente atraentes aos consumidores" (CAVALCANTI; FILATRO, 2016, p. 5).

No campo profissional, os colaboradores em design atuam em diferentes áreas, como exemplo: designer industrial (primeiro campo de atuação profissional, em que os profissionais tinham como foco a produção em massa de bens de consumo), designer gráfico (web designer, designer digital, designer de jogos), designer de moda, designer educacional ou instrucional, em suma, profissional responsável pela criação e solução educacionais, em que a aprendizagem humana é o objetivo principal da ação (FILATRO, 2008).

O design consiste na criação de algo como resultado de um processo, ou seja, como sendo o conjunto de uma série de atividades que se efetiva com regularidade, tais como: levantar as necessidades; solucionar os problemas; desenvolver soluções projetadas e implementar as soluções planejadas. O design como produto configura-se nas mais diferentes formas, podendo ser visuais, como exemplo, cores, texturas, entre outras; ou sensoriais, como linguagem, realidade virtual, entre outras (CAVALCANTI; FILATRO, 2016).

O design como modo de pensar foi proposto pela primeira vez em 1969, pelo epistemólogo Herbert Simon, em sua obra The science of the artificial, na qual define a ciência do design e fundamenta-se junto ao capítulo v - The science of design: creating the artificial, e capítulo vi - Social planning: designing the evolving artifact, do design como tudo o que se tem sido planejado pelo ser humano (SIMON, 1996).

De acordo com Simon (1996), o design deve estar preocupado com o formato que as coisas devem ser, buscando inventar artefatos para o alcance das metas exigidas pelo 
mercado profissional. Contudo, pensar na sua epistemologia, é pensar no saber contextualizado, holístico, crítico e criativo. Isso porque o design pertence a uma área do conhecimento na qual a criatividade é um conceito que ocupa uma posição central nas práticas projetuais. Essas práticas, conforme Loureiro (2017, p. 13) consistem em estratégias metodológicas que "contemplam o ensino prático reflexivo proposto por Schön (2000) e promovem uma cultura colaborativa e interdisciplinar favorecendo um desenvolvimento de habilidades necessárias em contextos de mudança e interação”. Ou seja, metodologias reflexivas, colaborativas, capazes de transformar uma dada realidade.

Schön (2000, p. 32) propõe uma prática docente na qual ressalta que o professor pode "[...] refletir no meio da ação, sem interrompê-la", resultando numa prática reflexiva. Assim, complementa que:

[...] sermos capazes de refletir-na-ação é diferente de sermos capazes de refletir sobre nossa reflexão-na-ação, de modo a produzir uma boa descrição verbal dela. E é ainda diferente de sermos capazes de refletir sobre a descrição resultante. Contudo nossa reflexão sobre nossa reflexão-na-ação passada pode conformar indiretamente nossa ação futura. (SCHÖN, 2000, p. 35-36)

A reflexão sobre a ação consiste na relação direta com a ação presente, versa sobre a reconstrução intelectual, ou seja, relembrar toda a ação para analisá-la, constituindo-se como um ciclo natural. A reflexão na ação consiste em observações e reflexões do profissional no momento de suas práticas pedagógicas. Essa reflexão deve gerar mudanças conscientes, promovendo soluções para possíveis problemas de aprendizagem. O pensamento crítico acerca de sua atuação, gera novas estratégias de atuação, ajustando-se, quando necessário. Por fim, a reflexão sobre a ação ocorre quando a ponderação sobre ações passadas resulta em novas práticas no futuro, o que geralmente ocorre ao término da aula.

Em vista disso, a relevância dos estudos sobre design está nas contribuições que esta possibilita ao saber elaborado. Para Loureiro (2017, p. 28), sua "prática ultrapassa as fronteiras do conhecimento". Conforme Alves (2016, p. 35), durante a elaboração do design de aprendizagem, é preciso “criar uma solução de aprendizagem pensando na 
experiência de quem aprende e no que esta pessoa precisa fazer com este aprendizado".

$\mathrm{E}$, dessa maneira, complementa que:

Ter o olhar de um designer de aprendizagem significa exercitar a visão de quem aprende, pensando em suas atribuições e desafios. É se despir da autoridade do conhecimento e se disponibilizar para encontrar maneiras de ajudar o outro a aprender o que ele precisa e não aquilo que você gostaria de ensinar. É facilitar a vida de quem aprende por meio da criação de uma solução de aprendizagem que vá tornar a execução do trabalho desta pessoa mais fácil, mais eficaz. (ALVES, 2016, p. 35)

Contudo, o termo Universal Design for Learning (UDL) ou "Design Universal para Aprendizagem" (DUA) inicialmente surge na área da arquitetura, a partir do desenvolvimento de produtos e design, denominado "design universal” (UD). A diferença basilar entre a UDL e UD é o foco na aprendizagem.

O UDL consiste no conjunto de princípios para o desenvolvimento curricular que dão a todos os indivíduos oportunidades iguais para aprender (CAST, 2012). O UD, terminologia formulada por Ron Mace (1941-1998), arquiteto e educador, abrange o desenvolvimento de edifícios, prédios, espaços, produtos, estruturas, em que se planeja atender as necessidades dos indivíduos com deficiências, em que destaca-se a área de engenharia civil na fase de design de produtos comerciais, desde projetos que incluíam a acessibilidades para pessoas com deficiências a projetos que melhorem e beneficiem as pessoas com deficiências auditivas, visuais, físicas (HALL; MEYER; ROSE, 2012).

O conceito de UDL foi definido pelos membros pesquisadores do Center for Applied Special Technology (CAST), organização educacional sem fins lucrativos, que visa o desenvolvimento de pesquisas na área educacional, com o objetivo de expandir as oportunidades de aprendizagem para todos os indivíduos por meio de um desenho universal (CAST, 2018). Baseia-se no conceito de que a diversidade é a regra, e não a exceção, portanto, pretende diminuir a principal barreira à aprendizagem e à participação dos alunos, que é o currículo acadêmico projetado de maneira uniforme, independentemente das diversidades existenciais em cada aluno. Ao reduzir as barreiras no contexto educacional, possibilita o aumento no desempenho do aprendiz. 
Fundada em 1984, a CAST conta com uma equipe de colaboradores multidisciplinares, o que inclui pesquisadores e educadores de nível internacional, que atuam em diferentes áreas: cientistas da educação, designer educacionais, analistas de políticas, designer gráficos, engenheiros de software, além de uma equipe administrativa e executiva. Pretende-se a partir de suas pesquisas criar soluções para os desafios da aprendizagem (CAST, 2018).

As pesquisas sobre UDL trouxeram, em especial, dois achados: (i) a aprendizagem individual é altamente diversificada e distribuída, e (ii) a aprendizagem entre diferentes indivíduos é também altamente diversificada e distribuída (CAST, 2012).

Noutro momento, as investigações científicas identificaram as práticas específicas fundamentais para apoio universal aos alunos, redesenhados no modelo teórico-prático com diretrizes que norteiam as medidas (CAST, 2012). O objetivo é garantir que os projetos de ensino abordem todas as estratégias de aprendizagem necessárias para alcançar também as pessoas com deficiências e que, portanto, parte do princípio universal, no sentido de atender as necessidades de todos os alunos (HALL; MEYER; ROSE, 2012).

O UDL é uma estrutura para a organização do currículo que se fundamenta em torno de três princípios: i) fornecer múltiplos meios de representação; ii) fornecer múltiplos meios de ação e expressão; e iii) fornecer múltiplos meios de envolvimento, baseados nas ciências da aprendizagem.

Os princípios do UDL fundamentam-se na neurociência, que se configura no estudo sobre o sistema nervoso, incluindo suas funcionalidades, estruturas e processos de desenvolvimento cognitivo, auxiliando no entendimento do processo de aprendizagem do ser humano. Esses princípios norteiam o desenvolvimento do desenho e do currículo, tornando-se eficaz quanto à inclusão de todos os aprendizes numa determinada situação didática (ROSE; GRAVEL, 2010).

De fato, esses princípios e estratégias, relacionadas ao desenvolvimento curricular pré-definidos no modelo UDL, permitem ao docente elaborar o planejamento didático, considerando a definição dos objetivos de ensino, e criação de materiais e avaliação que se adequem a todos os alunos, de maneira que todos possam aprender (CAST, 2018). Por 
outro lado, o UDL, quando aplicado ao currículo acadêmico, traz resultados favoráveis à aprendizagem discente (HALL; MEYER; ROSE, 2012), pois promove por meio de diferentes estratégias de ensino a igualdade de condições para o acesso e permanência no ambiente educacional, tendo em vista que consegue atrair e envolver os sujeitos participantes no processo educativo.

No contexto avaliativo, Russell e Airasian (2014) apresentam três momentos: o primeiro, a avaliação inicial, pretende identificar as características sociais, acadêmicas e comportamentais do aprendiz. Com base nessas informações, o professor toma decisões sobre as necessidades sociais, acadêmicas e comportamentais criando um ambiente favorável à aprendizagem. A segunda fase, avaliação instrucional, consiste no planejamento de instruções e inclui decisões sobre o que será ensinado, como e quais materiais serão utilizados, além de verificar o desempenho discente para, caso necessário, realizar possíveis ajustes no planejamento. A fase final, avaliação somativa, consiste nas decisões formais baseadas nos dados coletados sistematicamente no decorrer do ano, como atribuir notas, interpretar provas, recomendar os que necessitam de uma educação especial e identificar quais serão promovidos.

Algumas características são importantes para que o processo avaliativo ocorra de forma justa. Conforme afirmam Russell e Airasian (2014, p. 25), "para as informações de avaliação ajudarem a produzir decisões válidas, elas dependem se as informações das avaliações são adequadas". Desse modo, validade e confiabilidade são apresentadas como elementos fundamentais na avaliação. Para os autores, a validade está relacionada à adaptação e à importância das informações coletadas para uma tomada de decisão adequada. A confiabilidade refere-se à consistência das informações coletadas. Para que ocorra o aumento dessa confiabilidade nas avaliações, é necessário que haja diferentes coletas de informações sobre o comportamento e o desempenho. 


\section{Metodologia}

Este trabalho trata de estudo descritivo exploratório, com abordagem metodológica do tipo qualitativa (MINAYO, 2007). Caracteriza-se como descritivo, pois tem como objetivo apresentar as narrativas acerca da avaliação e do design universal de aprendizagem com base na percepção dos discentes do curso de Pedagogia de uma instituição pública do estado do Ceará.

A população objeto de estudo foi composta pelos discentes do curso de Pedagogia na modalidade semipresencial, regularmente matriculados, no período de 2018 na instituição pesquisada. Assim, a partir do universo representado por um total de 240 alunos regularmente matriculados distribuídos nos oito polos presenciais, foi selecionada uma amostra constituída por 110 alunos, conforme apresentado no Quadro 1.

Quadro 1 - Distribuição de entrevistas por polos presenciais

\begin{tabular}{|c|c|}
\hline Polos presenciais & $\mathbf{N}^{\circ}$ discentes respondentes \\
\hline Polo Beberibe & 16 \\
\hline Polo Brejo Santo & 13 \\
\hline Polo Caucaia (Flavio Marcílio) & 14 \\
\hline Polo Caucaia (Polo Araturi) & 15 \\
\hline Polo Itapipoca & 9 \\
\hline Polo Orós & 12 \\
\hline Polo Sobral & 21 \\
\hline Polo Russas & 10 \\
\hline Total & $\mathbf{1 1 0}$ \\
\hline
\end{tabular}

Fonte: Elaborado pelos autores (2018).

Neste estudo, realizou-se uma análise da percepção dos discentes sobre os desafios, limites e contribuições da aplicação dos princípios do design universal de aprendizagem na instituição pesquisada; desse modo, pretendeu-se investigar a avaliação do usuário-aluno quanto à aplicação desse modelo. 
Os questionários foram aplicados entre os meses de janeiro e fevereiro de 2018, apresentando três questões abertas, quais sejam: i) quais os desafios do UDL para a aprendizagem?; ii) quais as limitações do UDL para a aprendizagem?; e iii) quais as contribuições do UDL para avaliação do curso?

A análise qualitativa foi amparada na compreensão dos discursos provenientes dos discentes e embasada por meio do software Computer Assisted Qualitative Data Analysis Software - CAQDAS (Altas.ti 8), em sua versão 8.1 para Windows. As unidades hermenêuticas serviram de base para a discussão traçada, revelando desafios, limites e contribuições do modelo UDL.

A pesquisa considerou as orientações éticas durante a coleta e a análise dos dados. Todos os respondentes assinaram o Termo de Consentimento Livre e Esclarecido (TCLE). Ressalta-se que os entrevistados não foram identificados e foi mantido total sigilo das informações, as quais foram utilizadas apenas para o estudo. Cada respondente foi identificado por $R(n)$, a fim de manter o anonimato.

\section{Resultados e discussão}

Esta seção apresenta a avaliação do usuário-aluno quanto aos desafios, limitações e contribuições a partir da implementação do modelo UDL na instituição pesquisada.

Quando questionados quanto aos desafios do design universal para a aprendizagem nos cursos de graduação, os respondentes destacaram uma diversidade de situações-problemas, conforme apresentado na Figura 1. 
Figura 1 - Rede elaborada com os elementos estruturantes dos desafios do UDL para aprendizagem do curso

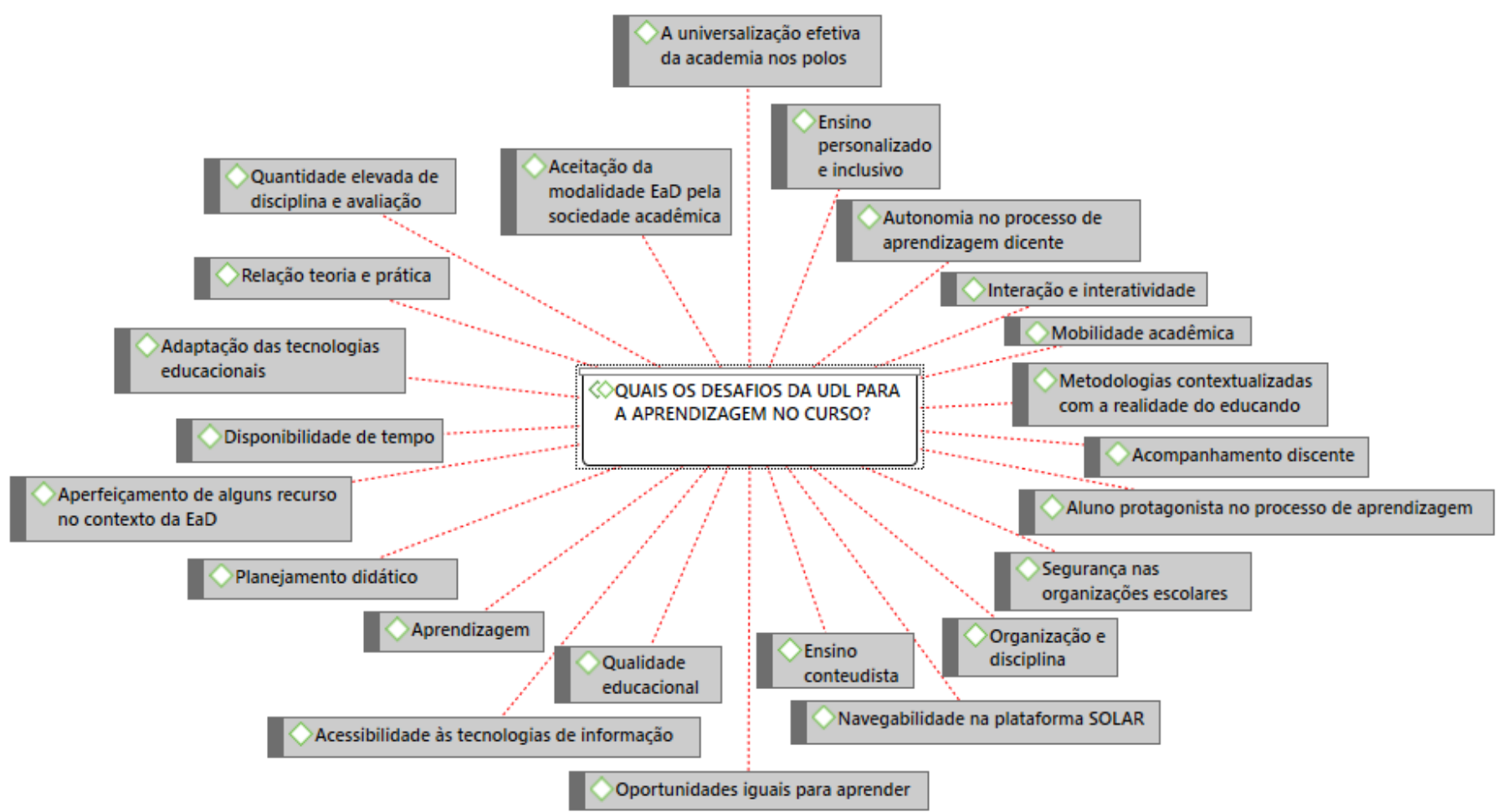

Fonte: Elaborado pelos autores (2018).

Dentre as respostas dos participantes, destacam-se:

Precisamos de muito para chegarmos a um nível de aprendizagem de excelência, como por exemplo, ensino mais personalizado e com mais inclusão. (R1, 2018.)

Falta de materiais complexos no nosso sistema, materiais mais claros. (R29, 2018.)

Adaptação do modelo com as formas tradicionais de ensino. $(R 75,2018$.

Colaboração e presença do professor. (R100, 2018.)

Adaptação às peculiaridades de cada aluno. Ainda que o curso com ferramentas variadas, ainda há uma "massificação", um certo "padrão" de como devemos agir dentro do curso. (R104, 2018.)

De acordo com os respondentes, observou-se que dentre os desafios não basta tornar o ensino acessível a todos, é preciso ainda refletir sobre as individualidades do seu alunato. De acordo com o participante R104, por vezes, os termos "massificação" e 
“democratização” são utilizados na educação superior como sinônimos. Conforme Silva Júnior e Sguissardi (2001), o capitalismo culmina no ensino massificado, pouco criativo e de baixa qualidade.

Libâneo enaltece que:

A educação de qualidade é aquela que promove para todos o domínio de conhecimentos e o desenvolvimento de capacidades cognitivas, operativas e sociais necessários ao atendimento de necessidades individuais e sociais dos alunos, à inserção no mundo do trabalho, a constituição da cidadania, tendo em vista a construção de uma sociedade mais justa e igualitária. (LIBÂNEO, 2001, p. 54)

Desse modo, esclarece que a busca pela qualidade educacional não será utopia.

O que as escolas precisam buscar, de fato, é a qualidade cognitiva das experiências de aprendizagem dos alunos [...] em consonância com as exigências sociais e educacionais contemporâneas significa prestar atenção nos conteúdos que estão sendo ensinados, na afetividade desses conteúdos para a vida prática. (LIBÂNEO, 2001, p. 56-57)

Diante disso, e de acordo com o participante R01, "ainda falta muito para chegarmos a um nível de excelência". É preciso que os governantes invistam em capacitação docente, aperfeiçoamento de recursos didáticos, melhorias em espaços escolares, para que isso se reflita na melhoria do desempenho do rendimento discente. Outro desafio da aplicação do modelo UDL é a própria resistência à inovação. De acordo com os respondentes, "o fato de cada aula, as vezes ser muito conteudista, com muito texto se torna chato" (R56), o que torna o momento de aprendizagem mecânico e superficial.

Conforme respondente R57, "algumas disciplinas há predominância de textos, dificultando a aprendizagem para aqueles alunos que têm melhor desempenho em áudio e imagem". Para Moran (2007, não paginado), a realidade evidenciada nas organizações educacionais mostra que ainda "predominam os modelos de design fechado, de roteiros com sequências de materiais e atividades iguais para todos, com ênfase mais no conteúdo do que nas competências e nas necessidades de cada estudante". 
De fato, ainda é preciso investir em metodologias ativas, conforme afirmação do discente R61: "Os recursos ainda precisam de aprimoramento para aprendizagem do aluno”. "Metodologias ativas são estratégias de ensino centradas na participação efetiva dos estudantes na construção do processo de aprendizagem, de forma flexível, interligada" (MORAN, 1994, p. 2).

Como estratégia, Mattar (2013) sugere a inserção de jogos analógicos e digitais, o uso de gamificação, bem como, de atividades com ênfase na experimentação e criatividade, como por exemplo, narrativas e histórias dinâmicas, construídas em colaboração pelos alunos, além de portfólios que identifiquem o progresso do desempenho do estudante.

No que se refere às limitações, conforme os participantes da pesquisa, houve uma grande variedade de respostas, desde a questão das metodologias de ensino até o acompanhamento tutorial, conforme apresentado na Figura 2.

Figura 2 - Rede elaborada com os elementos estruturantes das limitações da UDL

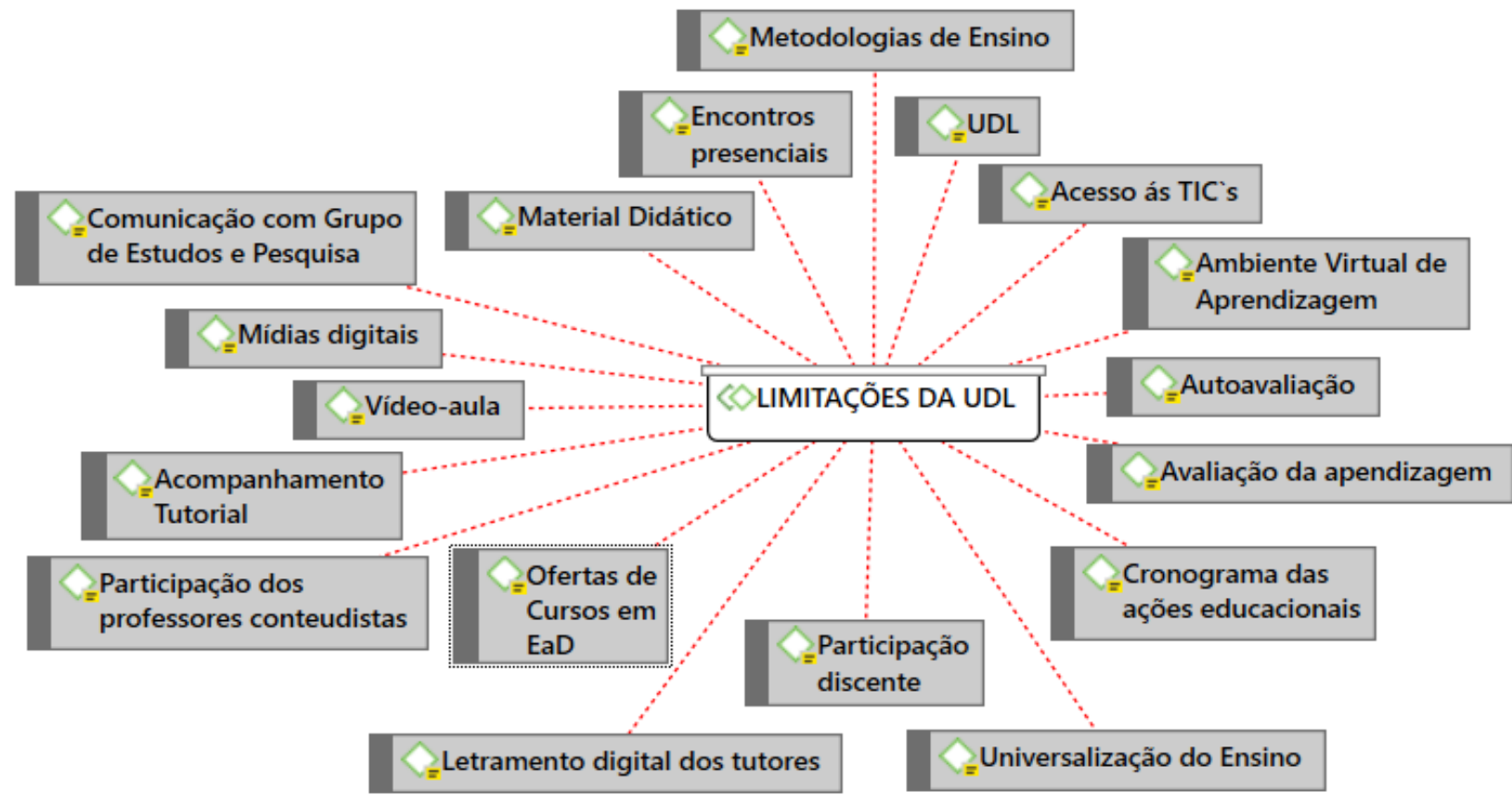

Fonte: Elaborado pelos autores (2018). 
A rede construída no Atlas Ti, na Figura 2, apresenta as 18 categorias extraídas das citações dos respondentes. Dentre as respostas, destacam-se:

São muitas limitações, poderia melhorar em vários aspectos, exemplos: as mídias digitais. (R10, 2018.)

Os docentes buscam e precisam estar cientes que cada aluno tem seu desenvolvimento, ou seja, é preciso métodos os quais supram as necessidades. (R33, 2018.)

A mais significativa é ter que me enquadrar num padrão definido por outros de forma, muitas vezes arbitrária. (R104, 2018.)

Poucos materiais de apoio, falta de material de autoavaliação e feedback. (R108, 2018.)

A participação dos tutores (no caso, a ausência) não por parte deles, mas a questão da modalidade. (R109, 2018.)

No que se refere aos limites quanto a aplicação do UDL, a maioria dos respondentes destacam as "mídias digitais", "acesso às TICs", "acessibilidade aos deficientes", "participação mais ativa de alguns tutores", e o aprimoramento da plataforma virtual de aprendizagem SOLAR para facilitar a aprendizagem.

O participante R104 destacou o ensino padronizado, o que vai contra a ideia do design universal. Conforme CAST (2011), a UDL consiste no conjunto de princípios para o desenvolvimento curricular que dá a todos os indivíduos oportunidades iguais para aprender. O participante R108 destacou a insuficiência dos materiais de apoio e de instrumentos de autoavaliação, além da inserção de mais feedbacks no decorrer do curso. Desse modo, os docentes precisam pensar em um planejamento didático mais flexível. Conforme o respondente R33, “os docentes buscam e precisam estar cientes que cada aluno tem seu desenvolvimento, ou seja, é preciso métodos os quais supram as necessidades".

Para Simon (1983, p. 21), “o animal existente em nós nos leva a agir de forma sequencial em relação a cada uma de nossas necessidades, criando, instintivamente, uma escala de prioridades para nossas necessidades". Ou seja, os seres humanos vivem em busca de seus objetivos e para o seu alcance precisam estar motivados a buscar o que Ihes satisfaz. 
Em relação às contribuições do design universal para avaliação do curso, os respondentes trouxeram uma variedade de elementos positivos, como por exemplo, metodologias de ensino, material didático, aprendizagem contextualizada, colaborativa e qualidade de ensino, conforme apresentado na Figura 3.

Figura 3 - Rede elaborada com os elementos estruturantes das contribuições do UDL para avaliação do curso

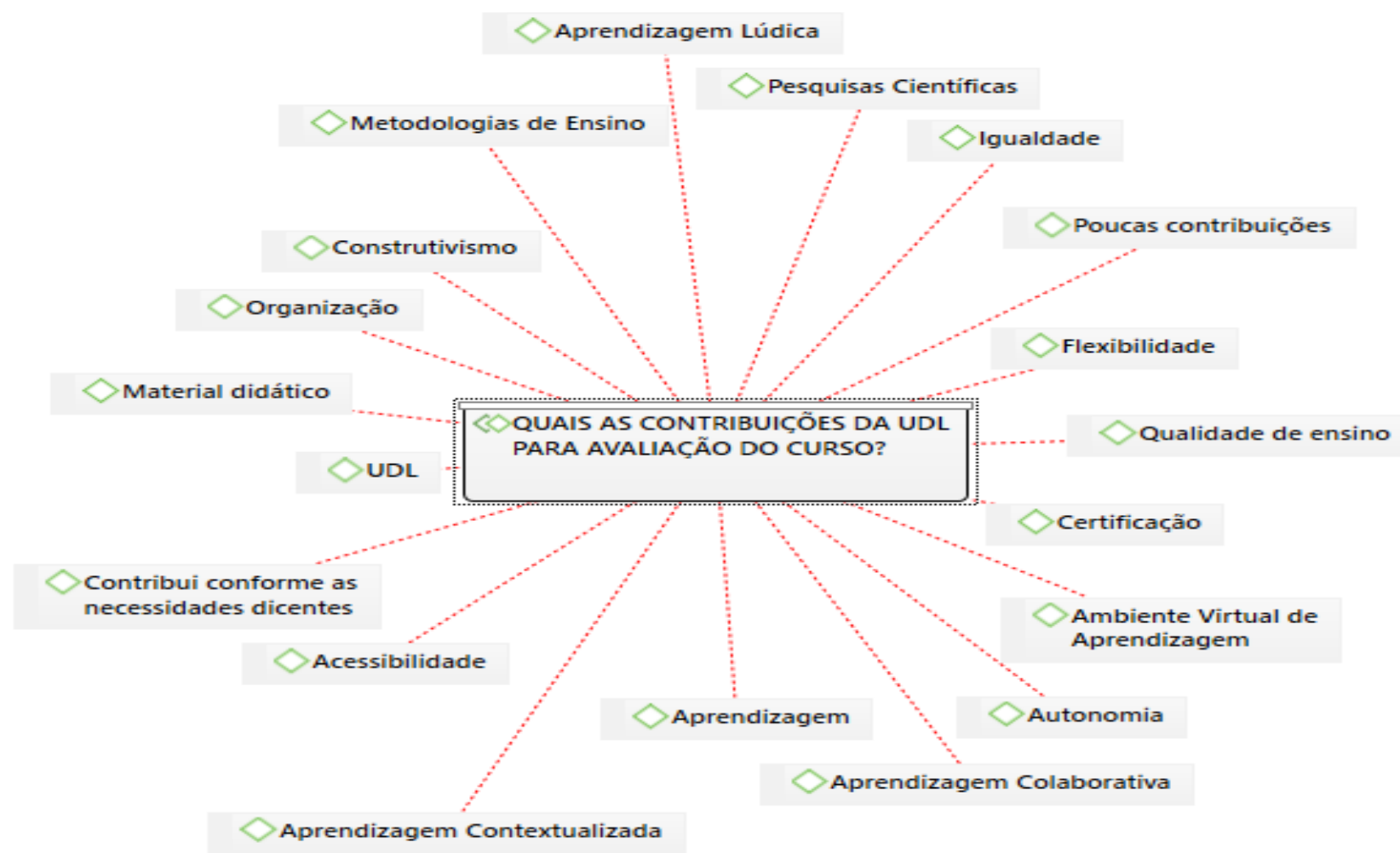

Fonte: Elaborado pelos autores (2018).

A rede construída no Atlas Ti, na Figura 3, apresenta as 19 categorias extraídas das citações dos respondentes. Dentre as respostas dos participantes, destacam-se:

Flexibilidade nas possibilidades de aprendizagem. (R62, 2018.)

Aprendizagem constante, dão destaques aos fóruns, onde os assuntos são capazes de se interligar, e ter acesso a maior informação que enriquecem a formação profissional. Além disso, tem muitas atividades que contextualizam os problemas de forma a trabalhar a solução. (R73, 2018.)

As variadas fontes de interação online/virtual são de grande relevância para a construção do conhecimento. (R102, 2018.) 
Ajuda na autonomia e acesso ao ensino por meio das tecnologias. (R105, 2018.)

A aplicação desse design alcança boa parte dos indivíduos, facilitando a aprendizagem em massa. (R107, 2018.)

O curso se torna um meio de igualar as oportunidades. (R110, 2018.)

Diante dos dados relatados, pode-se enumerar uma série de contribuições, resultando em práticas que promovam a aprendizagem discente, dentre as quais, a autonomia. Outras contribuições consistem na "flexibilidade nas possibilidades de aprendizagem" (R62) e igualdade de oportunidades. Em suma, os respondentes acreditam que o modelo UDL traz como benefício "uma aprendizagem diferenciada que ultrapasse os limites da educação tradicional, fazendo com que os alunos também passem e se tornar mais autônomos" (R67).

Assim sendo, a organização da atividade de ensino a partir dos princípios do design universal de aprendizagem pode revelar contribuições acerca da acessibilidade e, de modo especial, para a aprendizagem.

Contribuir de diferentes maneiras na eliminação de barreiras metodológicas nos contextos educacionais. Contudo, não basta a técnica pela técnica, ou apenas a aplicabilidade de metodologias sem a compreensão de quem são os sujeitos aprendentes. É preciso que o DUA seja mais que um framework, que ele se torne um princípio culturalmente aceito e vivido nos diferentes contextos. (BOCK; GESSER; NUERNBERG, 2018, p. 155)

A UDL procura minimizar as barreiras para a aprendizagem e maximizar o sucesso de todos os envolvidos no processo educativo. Para isso, busca transformar um currículo inacessível em um currículo acessível e democrático, o que envolve o processo de formação docente e o desenvolvimento de conhecimento e competências (EDYBURN, 2010; PACHECO, MARTELLO; BASTOS, 2016).

Tiziotto e Oliveira Neto complementam que:

A incorporação do design universal no material didático demonstra potencial para diminuir a evasão dos alunos, melhorar a avaliação do recurso de aprendizagem, aumentar a motivação e a participação, uma 
vez que permite a acomodação de uma ampla variedade de preferências e capacidades individuais. (TIZIOTTO; OLIVEIRA NETO, 2010, p. 8)

Desse modo, e partindo dos resultados obtidos, percebeu-se que oferecer a possibilidade de democratização de ensino poderá contribuir para efetivas contribuições, incluindo uma educação para além do tradicionalismo, realidade evidenciada nas organizações brasileiras.

De modo comparativo, a abordagem tradicional e a do UDL faz uso de recursos didáticos e metodológicos diferenciados (CAST, 2012). Enquanto na educação tradicional o ensino é conteudista e o professor é visto como transmissor do saber, o ensino concentra-se apenas no que é ensinado. Na abordagem UDL, o importante é como esse conteúdo será aprendido, de modo que o planejamento considera diferentes maneiras de ensinar, atendendo a diferentes tipos de alunos.

A metodologia de ensino, numa educação tradicional, tem como foco a exposição verbal de conteúdo e a resolução de exercícios, de modo a reforçar a memorização do que foi ensinado, valorizando apenas o resultado e as notas como desempenho do aluno. Na perspectiva UDL, as notas são utilizadas para o reforço do alcance dos objetivos de aprendizagem.

\section{Considerações finais}

A inclusão do design universal no contexto educacional trouxe inúmeras implicações, uma vez que vem contribuindo para gerar oportunidades iguais de aprendizagem. Dessa forma, conhecer o modelo de design inserido nas organizações educacionais é fundamental para entender as características, desafios, limites e suas contribuições para o alcance dos objetivos educacionais.

Diante do exposto, conclui-se que o objetivo principal do presente estudo, ou seja, apresentar as narrativas acerca da avaliação e design de aprendizagem, com base na percepção dos discentes do curso de graduação em Pedagogia, foi alcançado, haja vista que os dados resultantes do estudo permitiram observar que a utilização de um 
planejamento fundamentado nos princípios do design universais de aprendizagem contribui positivamente para o alcance dos objetivos educacionais.

Verificou-se que, conforme os respondentes, os desafios identificados quanto à incorporação do modelo UDL no cotidiano escolar, ainda é o ensino personalizado e inclusivo, além de utilização de metodologias contextualizada com a realidade do educando. Além da própria resistência à inovação, por parte dos professores.

Quanto às limitações identificadas pelos respondentes, constatou-se adequação as tecnologias educacionais contemplando os diferentes estilos de aprendizagem. Por vezes, o planejamento da ação didática faz uso apenas de texto em formato PDF ou vídeo-aulas, ao invés de ser melhor explorado outras mídias digitais para o aprimoramento da aprendizagem.

No que se refere às contribuições, evidenciaram-se oportunidades ampliadas de acesso e permanência na instituição escolar, planejamento mais flexível, desenvolvimento da autonomia, resultando no aprendizado acessível aos alunos, de modo a colaborar com a excelência do curso.

Diante dos fatos apresentados, constatou-se que o design universal nas organizações educacionais, constitui-se como um grande desafio, haja vista que pretende inserir uma mudança nas práticas pedagógicas que estão enraizadas no sistema educativo, numa concepção tradicional do papel da universidade e do professor, indo em busca de metodologias alternativas, democráticas e participativas. Ressalta-se, portanto, a necessidade de novas pesquisas, a fim de aprofundamento sobre as contribuições do design apresentadas pelos teóricos, tendo em vista que estudos sobre o UDL são iniciais no Brasil.

\section{Referências}

ALVES, Flora. Design de aprendizagem com uso de canvas. São Paulo: DVS, 2016. 
BOCK, Geisa Letícia Kempfer; GESSER, Marivete; NUERNBERG, Adriano Henrique.

Desenho universal para a aprendizagem: a produção científica no período de 2011 a 2016.

Revista Brasileira de Educação Especial, Bauru, v. 24, n. 1, p. 143-160, mar. 2018. Disponível em: http://www.scielo.br/scielo.php?script=sci_arttext\&pid=S1413-

65382018000100143\&lng=e n\&nrm=iso. Acesso em: 05 jan. 2018.

CAVALCANTI, Carolina Costa; FILATRO, Andrea. Design Thinking na educação presencial, a distância e corporativa. São Paulo: Saraiva, 2016.

CAST. Center for Applied Special Technology. Universal design for learning guidelines version 2.0. Wakefield, MA: Cast, 2011. Disponível em:

http://www.udlcenter.org/aboutudl/udlguidelines. Acesso em: 13 fev. 2018.

CAST. Center for Applied Special Technology. Design universal para aprendizagem.

Wakefield, MA: Cast, 2012. Disponível em: http://www.cast.org. Acesso em: 15 fev. 2018.

CAST. Center for Applied Special Technology. About Universal Design for Learning. Wakefield, MA: Cast, 2018. Disponível em: http://www.cast.org/udl/. Acesso em: 20 jan. 2018.

EDYBURN, Dave. Would you recognize universal design for learning if you saw it? Ten propositions for new directions for the second decade of UDL. Learning Disabilities Quarterly, Waltham, MA, v. 33, n. 1, p. 33-41, 2010. Disponível em: https://eric.ed.gov/?id=EJ909894. Acesso em: 20 jan. 2018.

FILATRO, Andrea. Design instrucional na prática. São Paulo: Pearson, 2008.

GOMES, Maria José et al. Evasão acadêmica no ensino superior: Estudo na área da saúde. Revista Brasileira de Pesquisa em Saúde, Brasília, v. 12, n. 1, p. 6-13, 2010. Disponível em: http://periodicos.ufes.br/RBPS/article/viewFile/278/191. Acesso em: 21 fev. 2018.

HALL, Tracey; MEYER, Anne; ROSE, David. Universal design for learning: questions and answers. In: HALL, Tracey; MEYER, Anne; ROSE, David. (orgs.). Universal design for learning in the classroom: practical applications. New York: The Guilford Press, 2012. Disponível em: https://www.guilford.com/excerpts/hall3.pdf. Acesso em: 20 fev. 2018.

LIBÂNEO, José Carlos. Didática. São Paulo: Cortez, 2001.

LOUREIRO, Michele Marconsini. Design para um aprendizado socioemocional: experiências no ensino fundamental. 2017. 113 f. Dissertação (Mestrado em Design) Pontifícia Universidade Católica do Rio de Janeiro - PUC-Rio, Rio de Janeiro, 2017. Disponível em: https://www.maxwell.vrac.puc-rio.br/30699/30699.PDF. Acesso em: 20 jan. 2018.

MATTAR, João. Aprendizagem em ambientes virtuais: teorias, conectivismo e MOOCs. Revista Digital de Tecnologias Cognitivas, São Paulo, n. 7, p. 20-40, 2013. Disponível em: 
https://www.pucsp.br/pos/tidd/teccogs/artigos/2013/edicao_7/2aprendizagem_em_ambie ntes_virtuais-joao_mattar.pdf. Acesso em: 22 jan. 2018.

MINAYO, Maria Cecilia; DESLANDES, Suely Ferreira. Pesquisa social: teoria, método e criatividade. 25. ed. rev. atual. Petrópolis: Vozes, 2007.

MORAN, José. Manuel. O que é educação a distância. Informe CEAD - Centro de Educação à Distância. SENAI. Rio de Janeiro, Ano 1, n. 5, p. 1-3, 1994. Disponível em: http://www2.eca.usp.br/moran/wp-content/uploads/2013/12/dist.pdf. Acesso em: 15 jan. 2018.

MORAN, José. Manuel. A educação que desejamos: novos desafios e como chegar lá. 2. ed. Campinas: Papirus, 2007.

PACHECO, Débora Pimentel; MARTELLO, Elisângela Luz Costa; BASTOS, Amélia Rota Borges de. Desenho universal para aprendizagem: Reflexões para uma prática pedagógica no ensino de ciências. In: SIMPÓSIO NACIONAL DO ENSINO DE CIÊNCIAS E TECNOLOGIAS, 5, 2016, Bagé. Anais [...] Bagé: UNIPAMPA, 2016. Disponível em: www.sinect.com.br/2016. Acesso em: 13 jan. 2018.

R1. [Entrevista cedida a] Maria Lucijane Gomes de Oliveira, Itapipoca (CE), 7 fev. 2018. R10. [Entrevista cedida a] Maria Lucijane Gomes de Oliveira, Beberibe (CE), 22 fev. 2018. R29. [Entrevista cedida a] Maria Lucijane Gomes de Oliveira, Brejo Santos (CE), 21 fev. 2018.

R33. [Entrevista cedida a] Maria Lucijane Gomes de Oliveira, Brejo Santos (CE), 21 fev. 2018.

R56. [Entrevista cedida a] Maria Lucijane Gomes de Oliveira, Sobral (CE), 8 fev. 2018.

R57. [Entrevista cedida a] Maria Lucijane Gomes de Oliveira, Sobral (CE), 8 fev. 2018.

R61. [Entrevista cedida a] Maria Lucijane Gomes de Oliveira, Sobral (CE), 8 fev. 2018.

R62. [Entrevista cedida a] Maria Lucijane Gomes de Oliveira, Sobral (CE), 8 fev. 2018.

R67. [Entrevista cedida a] Maria Lucijane Gomes de Oliveira, Sobral (CE), 8 fev. 2018.

R73. [Entrevista cedida a] Maria Lucijane Gomes de Oliveira, Caucaia (CE), 15 fev. 2018.

R75. [Entrevista cedida a] Maria Lucijane Gomes de Oliveira, Caucaia (CE), 15 fev. 2018.

R100. [Entrevista cedida a] Maria Lucijane Gomes de Oliveira, Caucaia (CE), 15 fev. 2018.

R102. [Entrevista cedida a] Maria Lucijane Gomes de Oliveira, Caucaia (CE), 15 fev. 2018.

R104. [Entrevista cedida a] Maria Lucijane Gomes de Oliveira, Caucaia (CE), 15 fev. 2018.

R105. [Entrevista cedida a] Maria Lucijane Gomes de Oliveira, Caucaia (CE), 15 fev. 2018. 
R107. [Entrevista cedida a] Maria Lucijane Gomes de Oliveira, Caucaia (CE), 15 fev. 2018.

R108. [Entrevista cedida a] Maria Lucijane Gomes de Oliveira, Caucaia (CE), 15 fev. 2018.

R109. [Entrevista cedida a] Maria Lucijane Gomes de Oliveira, Caucaia (CE), 15 fev. 2018.

R110. [Entrevista cedida a] Maria Lucijane Gomes de Oliveira, Caucaia (CE), 15 fev. 2018.

ROSE, David; GRAVEL, Jenna. Design Universal para Aprendizagem. In: PETERSON, Amy; BAKER, Joshua; MCGRAW, Hill. (eds.), Enciclopédia internacional da educação. Oxford, Reino Unido: Elsevier, 2010. p. 119-124.

RUSSELL, Michael; AIRASIAN, Peter. Avaliação em sala de aula: conceitos e aplicações. 7 . ed. Porto Alegre: AMGH, 2014.

SCHÖN, Donald. Educando o profissional reflexivo: um novo design para o ensino e a aprendizagem. Tradução de Roberto Cataldo Costa. Porto Alegre: Artmed, 2000.

SILVA JUNIOR, João dos Reis; SGUISSARDI, Valdemar. Novas faces da educação superior no Brasil: reforma do Estado e mudanças na produção. São Paulo: Cortez, 2001.

SIMON, Herbert Alexander. Reason in human affairs. Stanford: Stanford University Press, 1983.

SIMON, Herbert Alexander. The Sciences of the artificial. Massachusetts: MIT Press, 1996.

TIZIOTTO, Simone Aparecida; OLIVEIRA NETO, José Dutra de. Design universal: Solução para a acessibilidade no ensino superior a distância. In: CONGRESSO INTERNACIONAL DE EDUCAÇÃO A DISTÂNCIA, 2010, São Paulo, Anais [...] São Paulo: ABED, 2010. Disponível em: http://www.abed.org.br/congresso2010/cd/252010194434.pdf. Acesso em: 13 jan. 2018. 